\title{
A Brief Report on the Link between Perceived Coach Behaviour, Coach- Athlete Relationship Quality and Performance among South African Male Senior National Level Team Sport Para-Athletes
}

\author{
Julius Jooste ${ }^{1 \oplus}$, Ankebé Kruger ${ }^{2} \odot$ and Svenja Wachsmuth ${ }^{3} \odot$ \\ ${ }^{1}$ Northumbria University, United Kingdom, Department of Psychology \\ ${ }^{2}$ North-West University, South Africa, School for Human Movement Sciences. \\ ${ }^{3}$ Eberhard Karls University Tübingen, Germany, Research Group for Sport Psychology \& Methodology, Institute of Sport \\ Sciences \\ *Corresponding author: julius.jooste@ northumbria.ac.uk
}

\begin{abstract}
A fundamental feature in successful coaching outcomes and athlete performance is rooted in the quality of the coach-athlete relationship which is impacted by coaches' way of being. This investigation examined whether perceived coach behaviour associates with the coach-athlete relationship quality and self-rated season performance among members from two South African male senior national para-sport teams $(\mathrm{n}=23, M$ age $=32.65)$. The predictive utility of coaches' perceived behaviour on the dyadic relationship quality and athletes' views on their own performance was also determined. Cross-sectional quantitative data were collected by means of the Coaching Behaviour Scale for Sport, Coach-Athlete Relationship Questionnaire and a Likert-scale item recording athletes' subjective rating of perceived standard of performance for the respective competition season. The team members' reported fairly good standard of season performances and sound relationship standings with their involved head coaches who were seen to exhibit behaviours most illustrative of mental preparation, personal rapport, and competition tactics. Inferences drawn from the correlation analyses advised that particular adoptive coach behaviour in para-sport coaching appears to be a meaningful construct associated with the establishment and maintenance of relationships with athletes. Regression analyses also exposed coaches' competition strategy behaviour to be a significant predictor of complementarity in the coach-athlete relationship, which along with the noted positive correlations provide a good basis for further exploration in similar sport contexts.
\end{abstract}

\section{Keywords}

Coaching, Coach-Athlete Dyad, Disability Sport, Elite Athletes, Sports Performance

\section{INTRODUCTION}

Coach behaviour describes the manner in which coaches act or conduct themselves whilst performing coach related roles (Cote, Yardley, Hay, Sedgwick, \& Baker, 1999). Behaviour such as feedback, instruction and silence largely account (approximately 80\%) for almost all that sport coaches do in the inevitable strive to impact athletes' performance development and espouse control over the associative coaching environment
(Cushion \& Lyle, 2010). Distinction is made between supportive (i.e. emotional/relational \& structural/instrumental) and un-supportive (i.e. controlling, yelling, manipulating, threatening, \& intimidating) coach behaviour based on actions and strategies employed during training and competition which are essentially underscored by factors relating to the establishment of rapport with athletes as well as athletes' physical, technical, mental, and tactical preparation (Cote et al., 1999). 
Cumulative research findings in sport lend credence to accept that supportive coach behaviour can promote athletes' mental toughness (Nicholls, Morley, \& Perry, 2016), task-oriented coping, and sport achievement (Nicolas, Gaudreau, \& Franche, 2011), as well as to facilitate the motivational climate (Keegan, Harwood, Spray, \& Lavallee, 2014) and coach-athlete relationship (Nicholls, Levy, et al., 2016). Conversely, un-supportive coach behaviour causes not only unsolicited athlete anxiety and anger, but also impair athletes' levels of motivation and the quality of the coachathlete relationship (Keegan et al., 2014; Nicholls, Levy, et al., 2016). However, the ubiquitous socioenvironmental nature of coaching and coaches' behavioural dependence on athletes' individual refinements have both shifted and intensified research focus on the coach-athlete relationship as a central antecedent of athletes' optimal functioning (Choi, Cho, \& Huh, 2013; Jowett \& Shanmugam, 2016).

Jowett and Poczwardowski (2007) succinctly described the coach-athlete relationship as "a situation in which a coach's and an athlete's cognitions, feelings, and behaviours are mutually and causally interrelated". Jowett's (2007) 3+1Cs framework on the coach-athlete relationship conceptualises athletes and coaches mutually and causally interconnected cognitions, feelings, and behaviours into three main constructs namely commitment (intention to uphold the existing rapport, e.g. through making sacrifices), closeness (affective connection involving trust, care, concern \& support), and complementarity (cooperative \& affiliative attitude). The $+1 \mathrm{C}$ co-orientation represents the meta-perspective coaches and athletes hold (congruency between coach \& athlete) about the quality of the dyadic relationship in terms of closeness, commitment and complementarity (Jowett, 2007).

In this respect, a virtuous coach-athlete relationship is reported to be a desirable feature for athletes in their performance pursuits (Philippe \& Seiler, 2006). Moreover, investigations have underscored the facilitating effect individual facets of a high-quality coach-athlete relationship have on athletes' task and social cohesion (Jowett \& Chaundy, 2004), collective efficacy (Hampson \& Jowett, 2014), basic psychological needs (i.e. competence, autonomy \& relatedness) (Choi et al., 2013), positive affect (Davis \& Jowett, 2014), as well as performance and development (Jowett \&
Cockerill, 2003). However, poor coach-athlete relationships or conflict within the dyad may equally have a significant impact on athletes' emotions, cognitions, and performance (Mellalieu, Shearer, \& Shearer, 2013). Consequently, Wachsmuth and colleagues (2018) provided an account on the inextricable symbiotic nature of athlete-and-coach conflict responses (involving emotions, thoughts \& behaviours) attesting that one dyad member's dys/functional response determines the other member's retort. Thus, corroborating the impact that coach behaviour qualities have on both the formation and sustainability of a coach-athlete relationship.

Associative coach behaviour qualities noted to underscore the formation of a quality coachathlete relationship include harmonious passion, training and instruction, democratic behaviour (Anderson, 2018), intellectual stimulation, a consideration for athletes' individual needs and positive role modelling (Vella, Oades \& Crowe, 2013). In contrast, analyses of athletes' accounts revealed that the dyadic relationship is mostly undermined by an autocratic coach behaviour (Anderson, 2018) along with a coach's emotive disinclination, pretence and aloofness (Jowett, 2005). Despite these aforementioned deductions from athletes' estimations and other studies which have independently examined the impact of coach relationships or coach behaviours on athlete outcomes, literature on the examination around the interplay of these variables (Jowett, Nicolas, \& Yang, 2017) and associative perception on performance remains dearth. On this point, extant literature reveals that a coach's autonomysupportive behaviour towards athletes can bring about a high quality-athlete relationship (Lafrenière, Jowett, Vallerand, \& Carbonneau, 2011) and that closeness in the relationship is predictive of low levels of a coach's negative personal rapport (Jowett et al., 2017).

Notwithstanding, these limited findings are either based on the analyses of the viewpoints held by individual coach nominated athletes from different coach-athlete' dyads (Lafrenière et al., 2011) or from a large heterogeneous sample of French individual and team sport athletes from different levels of participation which does not account for differences noted in coach behaviour preferences between male, female (Lindauer, 2000), individual, team sport (Baker, Yardley, \& Cote, 2003), and cross-national athletes 
(Chelladurai, Imamura, Yamaguchi, Oinuma, \& Miyauchi, 1988). Thus, more research on the interplay between perceived coach behaviour and the coach-athlete relationship, as well as the link with performance is warranted, especially within a broader range of unexplored sport settings such as para-sport (Culver \& Werthner, 2018).

Para-sport (disabled sport) is an adapted version of abled-bodied sport with amended rules or equipment to accommodate athletes with disabilities or impairments referred to as paraathletes (Zealand, 2019). Initial research investigating para-athletes and coaches' relational experiences indicated particular differences and difficulties of working in such settings. For example, para-athletes described inner conflicts of wanting to be treated "the same but different", reported feelings of being treated as "lesser" athletes or not being understood by their coaches, or requiring different training methods which coaches were not trained to provide (Martin \& Whalen, 2014). Correspondingly, coaches perceived to lack specialized training necessary for working with para-athletes and complained about insufficient guidance and support from sporting organisations (e.g. in terms of professionalization and financial resources). To overcome these difficulties and thus facilitate individuals' development, para-sport coaches and athletes have emphasized the importance of mutual understanding and trust, open communication and shared learning experiences (Fairhurst, Bloom, \& Harvey, 2017; Wareham, Burkett, Innes, \& Lovell, 2017).

In view of athletes' increased physical as well as emotional vulnerability within para-sport settings, research examining the coach behaviour and the relational intricacies between athletes with disabilities or impairment who are often coached by abled-bodied coaches, is merited. In light of coaching being a product of athlete and environment, and often measured by the criteria of athletes' success and coach-athlete relationship, the primary aims of this investigation was to contribute to the literature by (a) examining the associations between perceived coach behaviour, coach-athlete relationship quality, and subjective season performance and (b) determining whether perceived coach behaviour is a likely predictor of the coach-athlete relationship quality and self-rated season performance among a sample of South African male senior national level team sport para- athletes. In review of extant research on supportive coach behaviour in able-bodied sport, it is hypothesised that team sport para-athletes who perceive their coaches to display higher approximations of support towards athletes' attainment of goals, mental preparation, and competition strategies, as well as who offer a sense of personal rapport are more likely to hold a quality relationship (closeness, commitment \& complementarity) with their coaches and have a better self-perceived standard of season performance.

Not only is there a conspicuous lack of knowledge and practical guidelines on effective coach behaviour and the interplay with athlete connectedness and performance in disabled sport, but also on the selection, formal training and development of coaches in this context (Martin \& Whalen, 2014; Townsend, Smith, \& Cushion, 2015). The present inquiry offers scientific means to support further exploration in similar contexts, and provides a logical response towards the refinement in coaching male team sport paraathletes. Supported findings could potentially inform para-sport coaches' philosophies and formal developmental frameworks on the important interaction between the involved psychosocial constructs.

\section{METHODS}

\section{Participants and Procedure}

A convenient sample of willing para-athletes from two South African (SA) male senior national sport teams [wheelchair basketball $(\mathrm{n}=16) \&$ visually impaired cricket $(\mathrm{n}=7)$ team players $(\mathrm{n}=$ 23, $M$ age $=32.65, S D=6.62$ years) $]$ participated in the investigation. The inclusion criteria required that each athlete represented SA at a senior national level during the 2017/2018 competitive season, was 18 years or older, be proficient and articulate in English along with holding a physical/psychological state which enabled them to accurately respond to the involved questionnaires. The majority $(56.3 \%)$ of participants competed at a senior national level for three or more years while eight participants reported their disability to be congenital and fifteen acquired their impairment at some stage in their life.

Permission to conduct the study was granted

by the Research Ethics Committee (Ref 
\#:FCRE2017/06/009SCI) of the principal investigator's institution at the time of research. Data were collected by means of a multi-section pen-and-paper questionnaire package satisfying the criteria of a quantitative cross-sectional study design. Participants underwent an information session detailing the aim, procedures and participation requirements prior to data collection. The assurance was given that participation was voluntary; responses will be kept anonymous and confidential, and that withdrawal from the study is permitted at any time without requiring a reason. The visually impaired athletes completed the questionnaire package using their everyday reading devices and by way of a verbal response to each item for those who have opted to complete the questionnaire in such a way. Respondents took approximately 25 minutes to complete the questionnaire package which was administered by the principal investigator.

\section{Measures}

Demographic data (age, nature of the disability, status of disability such as acquired or congenital, and years of participation at the national level), and the athlete's "perceived standard of performance for the current season" rated on a five point Likert-scale (with items $1=$ very poor, $2=$ poor, $3=$ average, $4=$ good, $\& 5$ very good) were obtained in the questionnaire package.

\section{Coaching Behaviour Scale for Sport (CBS-S)}

The CBS-S (Cote et al., 1999) is a selfreport questionnaire which assesses athletes' perceptions of their coach's behaviour and strategy during training, competition, and organisational settings. The CBS-S consists of 47 items representative of seven dimensions: Physical training and planning (7 items); Technical skills (8 items); Goal setting (6 items); Mental preparation (5 items); Competition strategies (7 items); Personal rapport (6 items); Negative personal rapport (8 items). Response options are provided on a 7-point Likert-scale that ranges from 1 (Never) to 7 (Always). Example items are "My coach provides advice on how to perform under pressure" (Mental preparation), "My coach helps me identify strategies to achieve my goals" (Goal setting), "My coach helps me focus on the process of performing well" (Competition strategies). Psychometric properties of the instrument in regard to factor structure $(\operatorname{MLR} \chi 2[734, \mathrm{n}=519]=$ 1941.11, $\mathrm{p}<.001 ; \mathrm{CFI}=.933$, TLI $=.906$, RMSEA $=.056$, SRMR $=.024)$, internal validity (ranging from .85 to .97 ) and re-test reliability (.49 to .90) have been established within previous studies (Cote et al., 1999; Koh, Kawabata, \& Mallett, 2014). Items (15 items) about physical training and planning, and technical skills of the sport were excluded from the questionnaire package as the study focused on the head coach's relational behaviours rather than on aspects such as physical training and planning which in the case of this sport context (the involved teams) was also fulfilled by different members of the coaching staff. The CBS-S offers a key benefit as it reports a multidimensional aspect to coaches' discrete behaviours (Koh et al., 2014).

\section{Coach-Athlete Relationship Questionnaire (CART-Q)}

The CART-Q (Jowett \& Ntoumanis, 2004) is a brief (11 items) self-report instrument which measures affective, cognitive, and behavioural interpersonal aspects in the coach-athlete relationship. Three items measure the construct of Commitment (e.g. "I feel committed to my coach"), whilst four items each measure the constructs of Closeness (e.g. "I trust my coach") and Complementarity (e.g. "When I am coached by my coach, I feel responsive to his/her efforts") on a 7-point Likert scale ranging from 1 (Strongly disagree) to 7 (Strongly agree). Internal consistency for all three subscales have been shown to reach satisfactory levels with Cronbach's alpha values ranging between .82 and .88 (Jowett \& Ntoumanis, 2004).

\section{Statistical Analysis.}

The computer-based IBM Statistical Package for Social Sciences (SPSS-Version 24) was used to analyse the data. Descriptive statistics such as minimum and maximum values, means, and standard deviations were used to screen the data. The reliability of the instruments was assessed by means of Cronbach's alpha coefficients. Pearson's correlation coefficient was used to determine the relationships between perceived coach behaviour, coach-athlete relationship quality, and self-rated standard of performance for the respective competition season. The relative influence perceived coach behaviour has on the coach- 
athlete relationship quality, and players' self-rated performance was determined through a series of simple linear

regression

analyses.

\section{RESULTS}

Table 1 contains the descriptive statistics, reliability coefficients, and correlation for all main variables of the study. Overall, participating athletes' evaluated their standard of performance for the season as fairly good $(M=3.69)$ and also reported high quality relationships (total $M=5.64$ ) with their respective coaches. The coaches in general were seen to adopt behaviours and strategies most demonstrative of mental preparation, personal rapport, and tactics for competition. Acceptable Cronbach's Alpha values ranging from 0.77 to 0.94 were recorded for the involved subscales. Coaches' behavioural strategies involving mental preparation, goal setting, competition strategies, and personal rapport were positively and significantly associated with each of the three coach-athlete relationship dimensions (commitment, closeness, complementarity) respectively.

Table 1: Descriptive Statistics, Reliability Coefficients And Pearson's Correlation of İnstruments Employed

Minimum Maximum Mean $\begin{gathered}\begin{array}{c}\text { Standard } \\ \text { Deviation }\end{array} \\ \begin{array}{c}\text { Cronbach's } \\ \text { Alpha }\end{array}\end{gathered} \quad \begin{array}{lllllllllllll} & 1 & 2 & 3 & 4 & 5 & 6 & 7 & 89\end{array}$

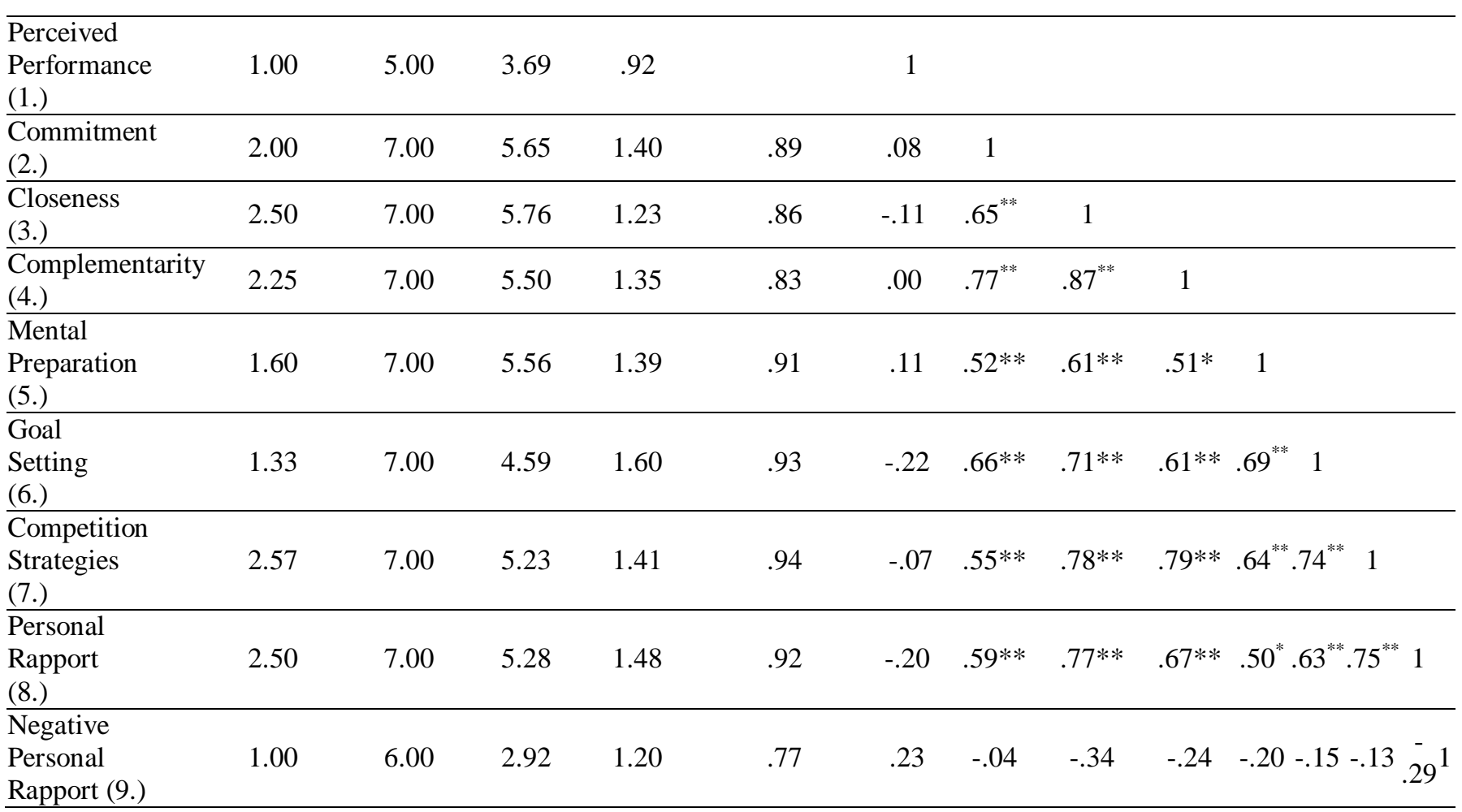

For the simple linear regression model, the variance recorded for each coach behaviour dimension (predictor variables) ranged from $27.4 \%$ to $74.7 \%$ with coaches' competition strategy behaviour $[\mathrm{F}(5,17)=6.51, \mathrm{P}<0.01]$ emerging as a significant predictor of complementary in the coach-athlete relationship ( $\beta$ $\left.=.68^{*}, p \leq 0.05\right)($ Table 2$)$.
None of the predictor variables exerted any significant influence on athletes' subjective season performance ratings $[\mathrm{F}(5,17)=1.29, \mathrm{P}<0.01]$. 
Table 2: Linear Regression Analyses of The Predictive Utility Coach Behaviour Has on The CoachAthlete Relationship Quality And Self-Rated Performance

\begin{tabular}{ll} 
Variable & Coach Behaviour in Sport Scale Variables \\
\hline Perceived & $\Delta R^{2}=.06, F(5,17)=1.29$ \\
Performance & MenPrep $\beta=.56$, GoalSet $\beta=-.60$, CompStrat \\
& $\beta=.15$, PersRap $\beta=-.14$, NegPersRap $\beta=.24$ \\
\hline \multirow{3}{*}{ Commitment } & $\Delta R^{2}=.38, F(5,17)=3.64$ \\
& MenPrep $\beta=.15$, GoalSet $\beta=.44$, CompStrat $\beta$ \\
& $=-.13$, PersRap $\beta=.38$, NegPersRap $\beta=.15$ \\
\hline \multirow{2}{*}{ Closeness } & $\Delta R^{2}=.67, F(5,17)=10.10$ \\
& MenPrep $\beta=.08$, GoalSet $\beta=.18$, CompStrat $\beta$ \\
& $=.33$, PersRap $\beta=.33$, NegPersRap $\beta=-.16$ \\
\hline & $\Delta R^{2}=.56^{*}, F(5,17)=6.51^{*}$ \\
Complementarity & MenPrep $\beta=-.03$, GoalSet $\beta=.02$, CompStrat $\beta$ \\
& $=.68(.02)$, PersRap $\beta=.13$, NegPersRap $\beta=-$ \\
& .12
\end{tabular}

\section{DISCUSSION}

The need for ongoing studies involving differently abled athletes is necessary to promote an ontological and epistemological platform that will guide understanding and improvement of contemporary coaching practices in para-sport (Townsend et al., 2015). The present investigation sought to examine whether perceived coach behaviour, coach-athlete relationship quality, and self-rated season performance are statistical associated and whether coach behaviour predict team sport para-athletes' views on the dyadic relationship quality and their own performance for the involved season. The results revealed that coaches mostly employed strategies related to mental preparation, personal rapport, and competition tactics within this particular sport setting. Athletes also reported a strong dyadic relationship status with their respective head coaches and relatively good self-rated season performance. Coaches' exhibition of behaviours with the intent of mentally preparing athletes as well as the provision of competition strategies is a logical approach in elite level sport as it permits a competitive edge over opponents and offers athletes a sense of conviction in the execution of deliberated tasks (Weinberg \& Gould, 2018). Additionally, coaches' ability to establish a harmonious relationship with their athletes not only paves the way for a productive working environment (Jowett, 2007), but also facilitates the satisfaction of athletes' basic needs (Jowett et al., 2017), and attainment of goals and successful performances (Jowett \& Cockerill, 2003).

Mainly, the significant positive associations noted between coaches' behaviours with regards to fostering mental preparation, goal setting, competition strategies, and personal rapport behaviour with each of the relationship dimensions are plausible as literature emphasized that empathic, supportive, directive and motivational coach behaviour fortify athletes' felt sense of a bond with their coaches (Jowett, 2007; Jowett \& Cockerill, 2003). Coaches' prominent display of goal related preparatory and relational behaviour in this context may inadvertently garner athletes' personal feelings of trust, appreciation, connectedness and responsiveness. These findings are supported by Jowett et al. (2017) who found similar results in a sample of able-bodied athletes in which it was concluded that the dyadic coachathlete relationship quality depends on how positive coach behaviour is perceived. Moreover, drawing on inferences forwarded by Wachsmuth and colleagues (2018), the athletes in the present study could have reciprocated their coaches' referred functional resolve with a corresponding 
sense of cooperation, closeness and commitment to the relationship. On this point, coaches' competition strategy behaviour emerged as a strong predictor of complementarity in the coachathlete relationship. This finding further highlights the temporal importance that coaches' ability to convey strategies in aid of para-athletes' performance goals play, in creating a sense of cooperation and affiliation towards the coachathlete relationship within athletes. This occurrence is credible considering the high appreciation and distinct preferences elite athletes' have for coaches who can offer meticulous game plans in aid of facilitating their developmental and performance endeavours (Becker, 2009).

It is worthy to note that self-rated season performance was not significantly associated with either perceived coach behaviour or the coachathlete relationship quality as initially hypothesised. Research revealed that team sport athletes spontaneously expect a greater emphasis on positive coaching behaviours compared to individual sport athletes due to the complex facets involved in team sport competition (Baker et al., 2003) which could in this unique sample have had less of a significant link with player's self-rated performance. Alternatively, coach behaviour related to physical training and technical knowhow (which were not evaluated in this investigation) might have had a stronger association with player performance as it was reported to be a desirable coaching preference among athletes (Sherman, Fuller, \& Speed, 2000). Although speculative, but the behaviours and relationship quality held between team members might be more relatable to players' self-perceived standard of performance in this context of team sport para-athletes due to the interdependent nature of team sport (Weinberg \& Gould, 2018) and mutual sharing and understanding of impairment,

which is not necessary the case when coached by able-bodied coaches. This notion may also attest the small and insignificant influence the relationship dimensions exerted on the team members' subjective season performance ratings.

Essentially, this preliminary findings lend some insight into the scarce knowledge available on the profound role coach behaviour plays in disabled sport. Results herein highlight coach behaviours which should be viewed complementary in establishing/retaining quality relationships with male team sport para-athletes. Nevertheless, it is advised that a larger confirmatory study is needed to verify the results presented on the small homogenous sample who were willing to participate in the present investigation. Para-athletes who meet the inclusion criteria set for the present investigation, are also not available in sizable numbers, especially in a developing context such as South Africa (Jooste \& Kubayi, 2018). It is, therefore, suggested that further research on the relational effects of coach behaviour on athletes' psychosocial status is conducted on heterogeneous samples from individual and team sport at varying levels of participation in order to fully elucidate understanding on the intricacies involved in coaching para-athletes. Scrutinising coaches' views on their own behaviour and the quality of the dyadic relations on athletes' objective longitudinal performance standards would further broaden understanding in this respect.

\section{CONCLUSION}

Despite the sport coaching literature's copious and covert focus on abled bodied athletes that is applied to athletes with disabilities (Dieffenbach \& Statler, 2012), para-sport coaches every so often lack the life experience of living with a disability which obstructs accurate understanding of para-athletes' psychological and sport-related needs (Wareham et al., 2017). Also, coaches do not always receive appropriate professional training directed at coaching paraathletes/sport (Crawford \& Stodolska, 2008; Wilson \& Khoo, 2013). The current results highlight the association between particular coach behaviours and establishing/retaining quality relationships with athletes within para-sport settings which is a worthy step towards addressing the suggested plea for furthering research and empirically supported practices for coach development in disabled sport (Roxas \& Ridinger, 2016). Findings of this study seemingly advocate Becker's (2009) proposed view that it is not only about what coaches do, but the behaviour they adopt when executing their role which in this context has proven to be positively associated with the quality of the bond that exists between coach and athlete. 
REFERENCES

Anderson, S.N. (2018). Exploring predictors of the coach-athlete relationship: passion, perfectionism, and leadership behaviors. Ithaca College Theses. https://digitalcommons.ithaca.edu/ic theses 1392

Baker, J., Yardley, J., \& Cote, J. (2003). Coach behaviors and athlete satisfaction in team and individual sports. International Journal of Sport Psychology, 34, 226 - 239.

Becker, A. J. (2009). It's not what they do, it's how they do it: athlete experiences of great coaching. International Journal of Sports Science \& Coaching, 4(1), 93-119.

Chelladurai, P., Imamura, H., Yamaguchi, Y., Oinuma, Y., \& Miyauchi, T. (1988). Sport leadership in a cross-national setting: the case of Japanese and Canadian university athletes. Journal of Sport and Exercise Psychology, 10(4), 374-389.

Choi, H., Cho, S., \& Huh, J. (2013). The association between the perceived coachathlete relationship and athletes' basic psychological needs. Social Behavior and Personality: an International Journal, 41(9), 1547-1556.

Cote, J., Yardley, J., Hay, J., Sedgwick, W., \& Baker, J. (1999). An exploratory examination of the coaching behavior scale for sport. Avante, 5(3), 82-92.

Crawford, J. L., \& Stodolska, M. (2008). Constraints experienced by elite athletes with disabilities in Kenya, with implications for the development of a new hierarchical model of constraints at the societal level. Journal of Leisure Research, 40(1), 128-155.

Culver, D., \& Werthner, P. (2018). Voices: para athletes speak. Qualitative Research in Sport Exercise and Health, 10(2), 167-175. doi:10.1080/2159676x.2017.1393004

Cushion, C., \& Lyle, J. (2010). Sports Coaching: Professionalisation and practice. Churchill Livingstone, Edinburgh.

Davis, L., \& Jowett, S. (2014). Coach-athlete attachment and the quality of the coachathlete relationship: implications for athlete's well-being. Journal of Sports Sciences, 32(15), 1454-1464.
Dieffenbach, K. D., \& Statler, T. A. (2012). More similar than different: the psychological environment of Paralympic sport. Journal of Sport Psychology in Action, 3(2), 109118.

Fairhurst, K. E., Bloom, G. A., \& Harvey, W. J. (2017). The learning and mentoring experiences of Paralympic coaches. Disability and Health Journal, 10(2), 240246. doi:10.1016/j.dhjo.2016.10.007

Hampson, R., \& Jowett, S. (2014). Effects of coach leadership and coach-athlete relationship on collective efficacy. Scandinavian Journal of Medicine and Science in Sports, 24(2), 454-460.

Jooste, J., \& Kubayi, A. N. (2018). Perceived coach leadership style and psychological well-being among South African national male wheelchair basketball players. Disability and Health Journal, 11(4), 655659. doi:10.1016/j.dhjo.2018.07.004

Jowett, S. (2005). The coach-athlete partnership. Psychologist, 18(7), 412-415.

Jowett, S. (2007). Coach-athlete relationships ignite sense of groupness. In group dynamics in exercise and sport psychology (pp. 81-96): Routledge.

Jowett, S. (2017). Coaching effectiveness: the coach-athlete relationship at its heart. Current Opinion in Psychology, 16, 154158.

Jowett, S., Adie, J. W., Bartholomew, K. J., Yang, S. X., Gustafsson, H., \& Lopez-Jimenez, A. (2017). Motivational processes in the coach-athlete relationship: a multi-cultural self-determination approach. Psychology of Sport and Exercise, 32, 143-152. doi:10.1016/j.psychsport.2017.06.004

Jowett, S., \& Chaundy, V. (2004). An investigation into the impact of coach leadership and coach-athlete relationship on group cohesion. Group DynamicsTheory Research and Practice, 8(4), 302311. doi:10.1037/1089-2699.8.4.302

Jowett, S., \& Cockerill, I. M. (2003). Olympic medallists' perspective of the althletecoach relationship. Psychology of Sport and Exercise, 4(4), 313-331.

Jowett, S., Nicolas, M., \& Yang, S. (2017). Unravelling the links between coach behaviours and coach-athlete relationships. 
European Journal of Sports and Exercise Science, 5(3), 10-19.

Jowett, S., \& Ntoumanis, N. (2004). The coachathlete relationship questionnaire (CART-Q): development and initial validation. Scandinavian Journal of Medicine and Science in Sports, 14(4), 245-257.

Jowett, S., \& Poczwardowski, A. (2007). Understanding the Coach-Athlete Relationship. In S. Jowett \& D. Lavallee (Eds.), Social Psychology in Sport (pp. 314). Champaign, Ill: Human Kinetics.

Jowett, S., \& Shanmugam, V. (2016). Relational coaching in sport: its psychological underpinnings and practical effectiveness. In R. J. Schinke, K. R. McGannon, \& B. Smith (Eds.), Routledge International Handbook of Sport Psychology (pp. 471484). Abingdon, Oxon: Routledge.

Keegan, R. J., Harwood, C. G., Spray, C. M., \& Lavallee, D. (2014). A qualitative investigation of the motivational climate in elite sport. Psychology of Sport and Exercise, 15(1), 97-107.

Koh, K. T., Kawabata, M., \& Mallett, C. J. (2014). The coaching behavior scale for sport: factor structure examination for singaporean youth athletes. International Journal of Sports Science \& Coaching, 9(6), 1311-1324. doi:Doi 10.1260/17479541.9.6.1311

Lafrenière, M.-A. K., Jowett, S., Vallerand, R. J., \& Carbonneau, N. (2011). Passion for coaching and the quality of the coachathlete relationship: the mediating role of coaching behaviors. Psychology of Sport and Exercise, 12(2), 144-152.

Lindauer, J. R. (2000). A comparison of preferred coaching leadership behaviors of college athletes in individual and team sports. (MSc in Exercise and Sport Science Physical Education Teaching), University of Wisconsin-La Crosse,

Martin, J. J., \& Whalen, L. (2014). Effective practices of coaching disability sport. European Journal of Adapted Physical Activity, 7(2).

Mellalieu, S., Shearer, D. A., \& Shearer, C. (2013). A preliminary survey of interpersonal conflict at major games and championships. Sport Psychologist, 27(2), 120-129. doi:DOI 10.1123/tsp.27.2.120

Nicholls, A. R., Levy, A. R., Jones, L., Meir, R., Radcliffe, J. N., \& Perry, J. L. (2016). Committed relationships and enhanced threat levels: perceptions of coach behavior, the coach-athlete relationship, stress appraisals, and coping among athletes. International Journal of Sports Science \& Coaching, 11(1), 16-26.

Nicholls, A. R., Morley, D., \& Perry, J. L. (2016). Mentally tough athletes are more aware of unsupportive coaching behaviours: perceptions of coach behaviour, motivational climate, and mental toughness in sport. International Journal of Sports Science \& Coaching, 11(2), 172-181.

Nicolas, M., Gaudreau, P., \& Franche, V. (2011). Perception of coaching behaviors, coping, and achievement in a sport competition. Journal of Sport and Exercise Psychology, 33(3), 460-468.

Philippe, R. A., \& Seiler, R. (2006). Closeness, coorientation and complementarity in coachathlete relationships: what male swimmers say about their male coaches. Psychology of Sport and Exercise, 7(2), 159-171.

Roxas, A. S., \& Ridinger, L. L. (2016). Relationships of coaching behaviors to student-athlete well-being. Academic Perspectives in Higher Education, 2(1), 10.

Sherman, C. A., Fuller, R., \& Speed, H. D. (2000). Gender comparisons of preferred coaching behaviors in Australian sports. Journal of Sport Behavior, 23(4).

Tawse, H., Bloom, G. A., Sabiston, C. M., \& Reid, G. (2012). The role of coaches of wheelchair rugby in the development of athletes with a spinal cord injury. Qualitative Research in Sport, Exercise and Health, 4(2), 206-225.

Townsend, R. C., Smith, B., \& Cushion, C. J. (2015). Disability sports coaching: towards a critical understanding. Sports Coaching Review, 4(2), 80-98.

Wachsmuth, S., Jowett, S., \& Harwood, C. G. (2018). On understanding the nature of interpersonal conflict between coaches and athletes. Journal of Sports Sciences, 36(17), 1955-1962. doi:10.1080/02640414.2018.1428882 
Wareham, Y., Burkett, B., Innes, P., \& Lovell, G.

P. (2017). Coaching athletes with

disability: preconceptions and reality. Sport in Society, 20(9), 1185-1202.

doi:10.1080/17430437.2016.1269084

Weinberg, R. S., \& Gould, D. S. (2018).

Foundations of sport and exercise psychology (7th ed.). Champaign, IL.: Human Kinetics.

Wilson, N. C., \& Khoo, S. (2013). Benefits and barriers to sports participation for athletes with disabilities: the case of Malaysia. Disability \& Society, 28(8), 1132-1145.

Zealand, P. N. (2019). About Para Athletes. Retrieved from www.paralympics.org.nz/ParaAthletes/About-Para-athletes 